\title{
ANALISIS SENTIMEN CALON GUBERNUR JAWA TIMUR 2018 DI TWITTER
}

\section{Sentiments Analysis for Governor of East Java 2018 In Twitter}

\author{
Ghulam Asrofi Buntoro \\ Prodi Teknik Informatika, Fakultas Teknik, Universitas Muhammadiyah Ponorogo \\ Universitas Muhammadiyah Ponorogo Jl. Budi Utomo No. 10 Ponorogo, 63471, Telp. (0352) 481124 \\ e-mail : ghulamasrofibuntoro@gmail.com
}

Received 27 / 11 / 2018, Revised 22 / 11 / 2018, Accepted 25 / 11 / 2018

\begin{abstract}
The enthusiasm of East Java Governor Election 2018 is also felt in the virtual world especially Twitter. All people freely argue about their respective governor candidates, memorandum raises many opinions, not only positive or neutral also negative opinions. Media growth is so rapid, revealing a lot of online media from the news media to social media. Today's social media is not only used for friendship, but also for other activities. Promos of trading or buying and selling, to political party promos or campaigns of candidates for regents, governors, legislative candidates through presidential candidates. The research objective is to conduct a method of Sentiments Analysis for Governor candidates East Java 2018 in twitter with optimal and maximum optimization. While the benefits are to help the community conduct research on opinions on twitter which contains positive, neutral or negative sentiments. Sentiments Analysis for Governor candidates East Java 2018 in twitter using non-conventional processes that save costs, time and effort. The results of Khofifah's dataset are $77 \%$ accuracy, $79.2 \%$ precision, $77 \%$ recall, $98.6 \%$ TP rate and $22.2 \%$ TN rate. For the results of GusIpul dataset, accuracy is $76 \%$, precision $74.4 \%$, recall $76 \%$, the TP rate is $93.8 \%$ and the TN rate is $52.9 \%$.
\end{abstract}

keywords — sentiment analysis, lexicon based features, naïve bayes classifier

\section{Pendahuluan}

Pemilihan Gubernur Jawa Timur tahun 2018 keramaiannya tidak hanya dirasakan di dunia nyata, di dunia maya khususnya media sosial Twitter orang-orang mulai membicarakan calon Gubernur jagoannya. Tahapan Pemilihan Gubernur Jawa Timur tahun 2018 sudah di umumkan Komisi Pemilihan Umum (KPU) Jawa Timur [1]. Sejak masih tahap pendaftaran sampai ditetapkannya siapa calon Gubernur Jawa Timur 2018 yang bakal maju di PILKADA Jatim 2018, nama-nama calonnya sudah mulai banyak diperbincangkan. Dunia maya yang begitu bebas dan sulit dikontrol, membuat semua orang bebas berpendapat atau beropini tentang calon Gubernur jagoannya masing-masing, memunculkan banyak opini-opini masyarakat, tidak hanya opini yang positif atau netral tapi juga yang negatif.

Perkembangan dunia informasi yang begitu cepat, memunculkan banyak media online, mulai informasi berita sampai media sosial atau pertemanan, media sosial mulai dari Facebook, Twitter, Path, Instagram, Google+ dan masih banyak lagi. Pada tahun 2015 Indonesia menjadi nomer dua pengguna aktif Media sosial Twitter dari jumlah total pengguna Twitter yang aktif seluruh dunia sampai saat ini 330 juta, jumlah Tweet yang dikirim per hari untuk seluruh dunia sekitar 500 juta dan jumlah pengguna harian yang aktif di seluruh dunia sekitar 100 juta [2]. 
Kemeriahan pilkada jawa timur 2018 sudah dirasakan di media sosial khususnya Twitter, media sosial khususnya twitter sekarang ini menjadi tempat yang sangat penting untuk calon dan tim suksesnya melakukan kampanye. Tim sukses sebuah pasangan calon gubernur atau kepala daerah sekarang ini misalnya, mereka sampai menghalalkan segala cara dalam mengkampanyekan calonnya, terbukti pada setiap masa kampanye banyak Black Campaign terutama di media sosial terhadap seorang calon. Jaman sekarang kampanye atau pencitraan tidak hanya dilakukan di dunia nyata tapi juga merambah di dunia maya. Media sosial khususnya Twitter sekarang ini menjadi salah satu tempat kampanye yang efektif dan efisien.

Analisis sentimen masih bagian dari penelitian opinion mining yaitu proses memahami, mengekstrak dan mengolah data tekstual secara otomatis untuk mendapatkan informasi sentimen yang terkandung dalam suatu kalimat opini [3].

Pada penelitian ini analisis sentimen dilakukan untuk melihat dan mengambil informasi sebuah opini seseorang dalam bahasa indonesia di Twitter yang ditujukan kepada calon gubernur jawa timur 2018, apakah opini itu masuk kategori opini positif, netral atau negatif. Metode pembobotan menggunakan Lexicon Based Features dan untuk menguji akurasi analisis sentimen dalam penelitian ini menggunakan dua metode yaitu metode Nä̈ve Bayes Classifier (NBC), karena metode tersebut banyak digunakan untuk analisis sentimen dengan hasil akurasi yang cukup bagus [4].

\section{Metode Penelitian}

Langkah-langkah penelitian sesuai dengan alur penelitian adalah sebagai berikut:

\subsection{Mengumpulkan data Tweet}

Data tweet diambil dengan metode Crawling dari media sosial Twitter. Data yang diambil hanya tweet dalam bahasa Indonesia mulai 17 Juni 2016 - 23 Juni 2018. Jumlah data seimbang, yaitu 100 tweet dengan kata kunci Gus Ipul dan 100 tweet dengan kata kunci Khofifah. Untuk lebih bervariasi data diambil secara acak baik dari user biasa ataupun media online di Twitter [5].

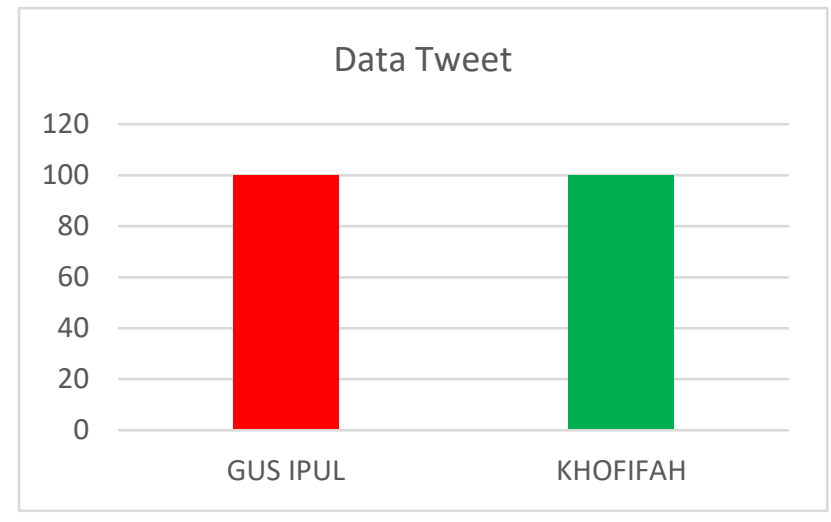

Gambar 1. Data tweet

\subsection{Preprocessing Data}

Pada tahap preprocessing, dilakukan 4 langkah sebagai berikut: 


\subsubsection{Seleksi komentar}

Pada tahap ini, dilakukan seleksi komentar yang mengandung hashtag Gus Ipul dan Khofifah (\#GusIpul dan \#Khofifah), dalam Twitter terdapat fungsi retweet, berguna untuk memberikan komentar terhadap tweet opini seseorang. Komentar tweet akan mengganggu dalam proses Analisis Sentimen, jadi dalam preprocessing ini komentar tweet dihapus.

\subsubsection{Cleansing}

Kalimat yang didapat biasanya masih terdapat noise [6], untuk itu, kita harus menghilangkan noise tersebut. Kata yang dihilangkan adalah karakter HTML, kata kunci, ikon emosi, hashtag (\#), username (@username), url (http://www.alamatwebsite.com), dan email (nama@alamatwebsite.com).

\subsubsection{Parsing}

Proses Parsing adalah proses memecah dokumen menjadi sebuah kata dengan melakukan analisa terhadap kumpulan kata dengan memisahkan kata tersebut dan menentukan struktur sintaksis dari tiap kata tersebut [7].

\subsubsection{Normalisasi Kalimat}

Tujuannya adalah untuk menormalkan kalimat opini sehingga kalimat dengan bahasa gaul menjadi normal atau baku [6]. Selain itu agar bahasa gaul tersebut dapat dikenali sebagai bahasa yang sesuai dengan KBBI. Yang harus dilakukan untuk normalisasi kalimat adalah:

a. Meregangkan tanda baca dan simbol selain alfabet adalah memberikan jarak terhadap tanda baca dari kata-kata sesudah atau sebelumnya, tujuannya agar tanda baca dan simbol selain alfabet tidak menjadi satu dengan kata-kata pada saat proses tokenisasi.

b. Mengubah menjadi huruf kecil semua

c. Normalisasi kata dimana aturan-aturan dalam proses normalisasi dapat dilihat pada Tabel 1.

Tabel 1. Aturan normalisasi kata [8].

\begin{tabular}{|l|l|}
\hline Tidak Normal / gaul & Normal \\
\hline Akhiran $-n y$ & Akhiran - nya \\
\hline Akhiran - nk & Akhiran - ng \\
\hline Akhiran $-\mathrm{x}$ & Akhiran - nya \\
\hline Akhiran $-\mathrm{z}$ & Akhiran $-\mathrm{s}$ \\
\hline Akhiran -dh & Akhiran $-\mathrm{t}$ \\
\hline Kata berulang: sama2 & Kata berulang: sama-sama \\
\hline Ejaan: oe & Huruf: $\mathrm{u}$ \\
\hline Ejaan: dj & Huruf: $\mathrm{j}$ \\
\hline
\end{tabular}


d. Menghilangkan huruf yang berulang, Contohnya: "hebaaat" untuk mengekspresikan kekaguman. Kata berulang seperti "hebaaat" akan di normalisasi menjadi "hebat".

\subsection{Tokenisasi}

Setelah normalisasi kalimat, selanjutnya kalimat tersebut dipecah kedalam token-token menggunakan pembatas atau delimiter spasi. Token yang digunakan dalam penelitian ini yaitu [9]: trigram: artinya Kalimat dipecah menjadi token-token dengan token yang terdiri dari tiga kata, contohnya: Komisi Pemilihan Umum.

\subsection{Load Dictionary}

Setelah dilakukan tokenisasi, langkah selanjutnya adalah load dictionary untuk. Banyak jenis kamus yang dapat digunakan, contohnya: kamus kata kunci sentimen positif (positif keywords), kamus kata kunci sentimen negatif (negatif keywords), kamus kata negasi (negation keywords), dan kamus normalisasi bahasa gaul atau alay. Berikut adalah contoh kamus dan isinya [8]:

a. Positif keywords: jujur, hebat, pandai, baik, keren, cerdas.

b. Negatif keywords: penipu, bohong, korupsi, jahat, jelek.

c. Negation keywords: sama, nggak, tidak, bukan, jauh.

d. Kamus konversi bahasa gaul ke KBBA: $\mathrm{sp}=$ siapa, $\mathrm{spt}=$ seperti, brp $=$ berapa

\subsection{Pembobotan Kata}

Setelah diketahui kata yang mengandung positif, negatif dan netral di dalam sebuah kalimat, selanjutnya dihitung bobot nilai yang terkandung dalam kalimat tersebut yang dilakukan dengan menjumlahkan nilai kata opini. Jika jumlah nilai opini dalam kalimat tersebut 1 , maka nilai sentimen dari kalimat tersebut adalah positif, jika nilai opini dalam kalimat tersebut $=0$, maka nilai sentimen dari kalimat tersebut adalah netral, jika nilai opini dalam kalimat tersebut $=-1$, maka nilai sentimen dari kalimat tersebut adalah negative [9].

Tabel 2. Nilai Sentimen

\begin{tabular}{|l|c|}
\hline Sentimen & Nilai \\
\hline Positif & 1 \\
\hline Netral & 0 \\
\hline Negatif & -1 \\
\hline
\end{tabular}

\subsection{Klasifikasi}

Masuk pada proses klasifikasi. Proses klasifikasi menggunakan WEKA 3.7.11. Metode klasifikasi yang digunakan dalam penelitian ini adalah Nä̈ve Bayes Classifier (NBC). NBC adalah metode classifier berdasarkan probabilitas dan Teorema Bayesian dengan asumsi bahwa setiap variabel $\mathrm{X}$ bersifat bebas (independence). Dengan kata lain, NBC mengansumsikan bahwa keberadaan sebuah atribut (variabel) tidak ada kaitannya dengan beradaan atribut (variabel) yang lain. Berikut adalah Rumusnya. 


$$
P(H \mid X)=\frac{P(H \mid X) P(H)}{P(X)}
$$

Pada proses klasifikasi data diuji dengan menggunakan metode 10-fold cross validation [10]. Jadi dataset akan dibagi menjadi dua, yaitu 10 bagian dengan 9/10 bagian digunakan untuk proses training dan 1/10 bagian digunakan untuk proses testing. Iterasi berlangsung 10 kali dengan variasi data training dan testing menggunakan kombinasi 10 bagian data.

\subsection{Evaluasi Hasil}

Melakukan evaluasi performa Akurasi, Presisi dan Recall dari eksperimen yang telah dilakuakan. Evaluasi dilakukan dengan menggunakan true positive rate (TP rate), true negative rate ( $T N$ rate), false positive rate ( $F P$ rate) dan false negative rate ( $F N$ rate) sebagai indikator. $T P$ rate adalah persentase dari kelas positif yang berhasil diklasifikasi sebagai kelas positif, sedangkan $T N$ rate adalah persentase dari kelas negatif yang berhasil diklasifikasi sebagai kelas negatif. FP rate adalah kelas negatif yang diklasifikasi sebagai kelas positif. $F N$ rate adalah kelas positif yang diklasifikasi sebagai kelas negatif [11].

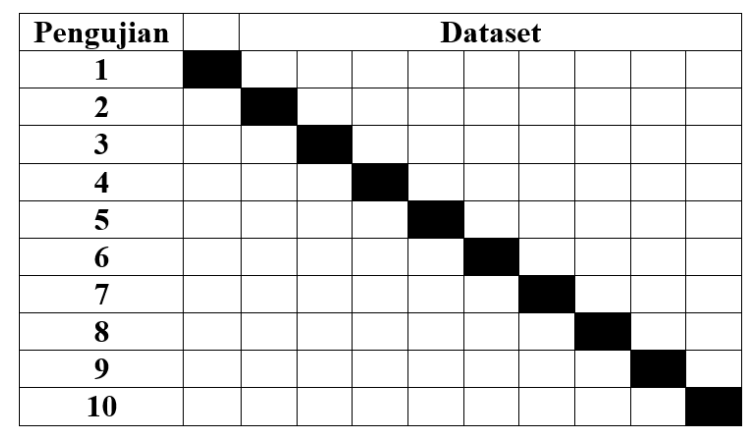

Gambar 2. Ilustrasi 10-fold cross validation

Tabel 3. Confusion Matrix

\begin{tabular}{|c|c|c|c|}
\hline \multicolumn{2}{|c|}{} & \multicolumn{2}{c|}{ Predicted } \\
\cline { 2 - 4 } & Negative & Positive \\
\hline \multirow{2}{*}{ Actual } & Negative & $a$ & $b$ \\
\cline { 2 - 4 } & Positif & $c$ & $d$ \\
\hline
\end{tabular}

\section{Pembahasan}

Hasil berupa data penelitian yang telah diolah dan dituangkan dalam bentuk tabel, grafik, foto atau gambar. Pembahasan berisi hasil analisis dan hasil penelitian yang dikaitkan dengan struktur pengetahuan yang telah mapan (tinjauan pustaka yang diacu oleh penulis), dan memunculkan teori-teori baru atau modifikasi terhadap teori - teori yang telah ada. 
Dataset pada penelitian ini menggunakan format ARFF yang dikumpulkan dari Twitter dengan metode Crawling dari media sosial Twitter. Data yang diambil hanya tweet dalam bahasa Indonesia, yaitu tweet dengan kata kunci GusIpul untuk Calon Gubernur Jawa Timur 2018 Syaifullah Yusuf dan Khofifah untuk Calon Gubernur Jawa Timur 2018 Khofifah Indar Parawansa. Data diambil secara acak baik dari user biasa ataupun media online di Twitter.

Dataset yang digunakan sebanyak 200 Tweet, data dibagi secara seimbang (balanced) setiap kelasnya, karena dengan data yang tidak seimbang (imbalanced), klasifikasi yang dibangun memiliki kecenderungan untuk mengabaikan minority class [11]. Data dibagi menjadi GusIpul 100 Tweet, dan Khofifah 100 Tweet. Pemberian label dilakukan dengan metode Lexicon Based Features dan bantuan ahli Bahasa Indonesia.

\section{Hasil}

Hasil Analisis Sentimen Calon Gubernur Jawa Timur 2018 menggunakan metode Lexicon Based Features dengan tiga class atribut yaitu positif, netral dan negatif.

Tabel 4. Hasil Analisis Sentimen metode Lexicon Based Features

\begin{tabular}{|c|c|c|}
\hline Sentimen & GusIpul & Khofifah \\
\hline Positif & 65 & 72 \\
\hline Netral & 18 & 19 \\
\hline Negatif & 17 & 9 \\
\hline
\end{tabular}

Untuk mengetahui akurasinya, Analisis Sentimen calon Gubernur DKI Jakarta 2017 dengan metode Lexicon Based Features diklasifikasi menggunakan metode Naïve Bayes Classifier (NBC) dengan perangkat lunak WEKA versi 3.8.1. WEKA menggunakan tipe dokumen Atribut-Relation File Format (ARFF) sebagai masukan untuk melakukan klasifikasi data.

Hasil dari proses klasifikasi kemudian diuji dengan menggunakan metode 10-fold cross validation, data dibagi mejadi 10 bagian dengan 9/10 bagian digunakan untuk proses training dan $1 / 10$ bagian digunakan untuk proses testing. Iterasi berlangsung 10 kali dengan variasi data training dan testing menggunakan kombinasi 10 bagian data.

Perbandingan hasil dari metode klasifikasi Naïve Bayes Classifier (NBC) dengan dataset Calon Gubernur Jawa Timur 2018 GusIpul dan Khofifah.

Tabel 5. Perbandingan Hasil Klasifikasi

\begin{tabular}{|l|l|l|l|l|l|}
\hline Calon Gubernur & Accuracy (\%) & Precision (\%) & Recall (\%) & TP Rate (\%) & TN Rate (\%) \\
\hline GusIpul & 76 & 74,4 & 76 & 93,8 & 52,9 \\
\hline Khofifah & 77 & 79,2 & 77 & 98,6 & 22,2 \\
\hline
\end{tabular}

*) Nilai Precision dan Recall meruapakan nilai rata-rata dari nilai kelas positif dan kelas negatif. 
Tabel 5. berisi informasi mengenai nilai akurasi, presisi, recall, TP rate dan $T N$ rate dari masing-masing uji coba yang telah dilakukan. Bagian kolom berisi informasi mengenai Calon Gubernur Jawa Timur 2018. Sedang bagian baris berisi nilai akurasi, presisi, recall, TP rate dan $T N$ rate dari masing-masing uji coba yang telah dilakukan. Dari proses data preprocessing menghasilkan sejumlah token yang kemudian digunakan sebagai input sebuah proses klasifikasi. Proses klasifikasi dilakukan menggunakan metode Nä̈ve Bayes Classifier (NBC). Dari proses klasifikasi diperoleh nilai akurasi, presisi, recall, TP rate dan TN rate dari masing-masing uji coba.

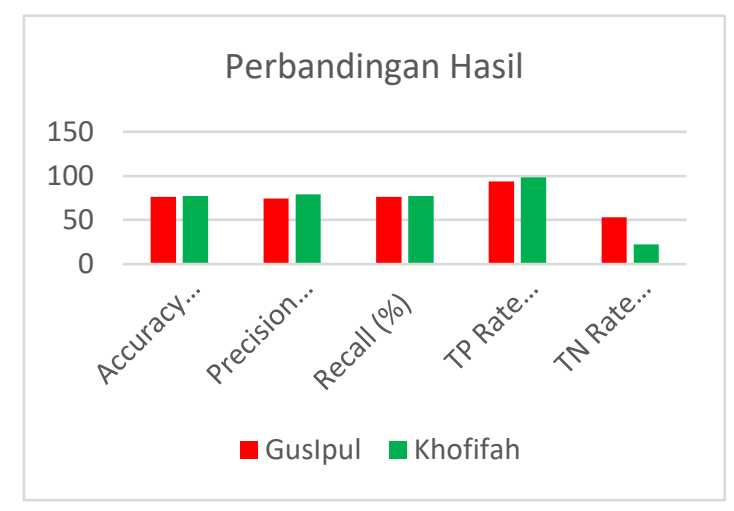

Gambar 3. Grafik tingkat akurasi

Dari Gambar 3. dapat dilihat hasil akurasi dari nilai Analisis Sentimen dengan metode Lexicon Based Features yang diklasifikasi dengan metode Naïve Bayes Classifier (NBC). Nilai akurasi dataset Khofifah mencapai $77 \%$, nilai presisi $79,2 \%$, nilai recall $77 \%$, nilai $\mathrm{TP}$ rate $98,6 \%$ dan nilai $T N$ rate $22,2 \%$. Untuk dataset GusIpul akurasinya mencapai $76 \%$, nilai presisi $74,4 \%$, nilai recall $76 \%$, nilai $T P$ rate $93,8 \%$ dan nilai $T N$ rate 52,9\%. Dataset Khofifah mendapatkan akurasi paling tinggi karena dari 72 data positif, 71 data berhasil diklasifikasi metode Nä̈ve Bayes Classifier (NBC) dengan benar sesuai sentimennya yaitu sentimen positif. Sedangan untuk dataset GusIpul, dari 65 data positif, 61 data berhasil diklasifikasi metode Nä̈ve Bayes Classifier (NBC) dengan benar sesuai sentimennya yaitu sentimen positif. Metode ini cenderung Nä̈ve Bayes Classifier (NBC) lebih stabil karena berbasis probabilitas kemunculan kata dalam sebuah kalimat.

Nilai akurasi adalah salah satu parameter penilaian dari metode yang telah digunakan, nilai akurasi didapat dari jumlah banyaknya data yang berhasil diklasifikasi dengan benar sesuai kelas sentimennya dari seluruh jumlah data yang diklasifikasi. Nilai akurasi yang tinggi didapat ketika banyak data yang berhasil diklasifikasi dengan benar sesuai kelas sentimennya.

Dari Gambar 3. dapat diketahui juga nilai Precision dan Recall. Nilai Precision mengikuti nilai akurasi, nilai akurasi semakin tinggi maka akan diikuti nilai Precision yang tinggi juga, begitu sebaliknya. Nilai Precision adalah jumlah data positif yang benar diklasifikasi sebagai data positif dibagi total data yang diklasifikasi sebagai data positif. Sedangkan Nilai recall adalah jumlah data positif yang benar diklasifikasi sebagai data positif dibagi jumlah data positif sebenarnya.

Dari Gambar 3. kita juga dapat mengetahui nilai TP Rate dan TN Rate. TP Rate adalah nilai data positif yang diklasifikasi dengan benar sesuai kelas sentimennya, yaitu positif. Nilai TN Rate adalah nilai data sentimen yang diklasifikasi dengan benar sesuai kelas sentimennya, yaitu negatif. 
Dari penelitian yang telah dilakukan, terbukti metode klasifikasi Naïve Bayes Classifier (NBC) dapat digunakan untuk mengklasifikasi sentimen-sentimen (positif, netral dan negatif) tweet Bahasa Indonesia terhadap Calon Gubernur Jawa Timur 2018. Selanjutnya, dataset Khofifah mendapat akurasi lebih tinggi dibandingkan dengan akurasi dataset GusIpul, dengan akurasi 77\% dibanding $76 \%$. Dalam dataset Khofifah, sentimen positifnya paling banyak yaitu 72 dan sentimen negatifnya hanya 9. Sedangkan didataset GusIpul sentimen positifnya 65 dan sentiment negatifnya 17. Jadi bisa disimpulkan, di media sosial Twitter Khofifah lebih banyak dicintai dibandingkan dengan GusIpul. Meskipun menghasilkan akurasi yang cukup tinggi, model yang dibangun ini masih melakukan sedikit kesalahan klasifikasi untuk dataset yang pembagian sentimennya tidak seimbang. Karena dengan menggunakan dataset yang tidak seimbang akan menyebabkan data minority class yang salah diklasifikasi sebagai data majority class (Kohavi, 1998). Pada akhirnya menjadikan selisih nilai menjadi besar.

\section{Kesimpulan}

Dari penelitian yang telah dilakukan, terbukti metode klasifikasi Nä̈ve Bayes Classifier (NBC) dapat digunakan untuk mengklasifikasi sentimen-sentimen (positif, netral dan negatif) tweet Bahasa Indonesia terhadap Calon Gubernur Jawa Timur 2018. Selanjutnya, dataset Khofifah mendapat akurasi lebih tinggi dibandingkan dengan akurasi dataset GusIpul, Hasil dataset Khofifah akurasi $77 \% \%$, nilai presisi $79,2 \%$, nilai recall $77 \%$, nilai $T P$ rate $98,6 \%$ dan nilai $T N$ rate $22,2 \%$. Untuk hasil dataset GusIpul akurasi $76 \%$, nilai presisi $74,4 \%$, nilai recall $76 \%$, nilai TP rate 93,8\% dan nilai TN rate 52,9\%. Dalam dataset Khofifah, sentimen positifnya paling banyak yaitu 72 dan sentimen negatifnya hanya 9. Sedangkan didataset GusIpul sentimen positifnya 65 dan sentiment negatifnya 17. Jadi bisa disimpulkan, di media sosial Twitter Khofifah lebih banyak dicintai dibandingkan dengan GusIpul. Terbukti Analisis Sentimen dapat digunakan untuk mengetahui Sentimen masyarakat khususnya netizen Twitter terhadap Calon Gubernur Jawa Timur 2018, sehingga membantu masyarakat awam untuk mengetahui sentimen masyarakat lainya terhadap Calon Gubernur Jawa Timur 2018. Untuk penelitian selanjutnya perlu dicoba dikembangkan dengan menggunakan data yang lebih banyak dan Real Time. Perlu dikembangkan juga stopword list dan stemmer Bahasa Indonesia yang mampu meningkatkan akurasi dalam analisis Sentimen Bahasa Indonesia.

\section{DAFTAR REFERENSI}

[1] KPU Provinsi Jawa Timur, "Kegiatan Tahapan Pilgub Jatim 2018 Makin Padat, Ketua Kpu Jatim Ajak Jaga Soliditas.” [Daring]. Tersedia pada:

https://www.google.com/search?client=firefox-b-

$\mathrm{d} \& \mathrm{q}=$ Kegiatan+Tahapan + Pilgub $+\mathrm{Jatim}+2018+$ Makin + Padat $\% 2 \mathrm{C}+$ Ketua $+\mathrm{Kpu}+\mathrm{Jatim}+\mathrm{Ajak}+\mathrm{J}$ aga+Soliditas. [Diakses: 08-Feb-2018].

[2] S. Aslam, Twitter by the Numbers (2018): Stats, Demographics \& Fun Facts. 2018.

[3] B. Liu, "Sentiment Analysis and Subjectivity.," Handbook of natural language processing, vol. 2, hlm. 627-666, 2010.

[4] D. S. Pamungkas, N. A. Setiyanto, dan E. Dolphina, "Analisis Sentimen pada Sosial MediaTwitter Menggunakan Naive Bayes Classifier Terhadap Kata Kunci 'Kurikulum 2013,'” Techno. Com, vol. 14, no. 4, hlm. 299-314, 2015. 
[5] G. A. Buntoro, T. B. Adji, dan A. E. Purnamasari, "Sentiment Analysis Candidates of Indonesian Presiden 2014 with Five Class Attribute," International Journal of Computer Applications, vol. 975, no. 136.2, hlm. 23-29, 2016.

[6] A. Nurfalah, "Analisis Sentimen Pada Opini Berbahasa Indonesia Menggunakan Pendekatan Lexicon Based," Bandung, Indonesia, 2011. [Daring]. Tersedia pada:

Http://Adiyasan.Wordpress.Com/2013/02/08/Sentiment-Analysis-Menggunakan-PendekatanLexicon-Based/. [Diakses: 10-Mar-2018].

[7] A. F. Hadi, D. B. CW, dan M. Hasan, “Text Mining pada Media Sosial Twitter Studi Kasus: Masa Tenang Pilkada DKI 2017 Putaran 2," Seminar Nasional Matematika dan Aplikasinya.

[8] G. A. Buntoro, "Data Preprocessing." [Daring]. Tersedia pada: https://www.google.com/search?q=apa + itu + noise + dalam + data + mining\&ie=utf- $8 \&$ oe $=u t f-$ $8 \&$ aq=t\&rls=org.mozilla:en-US:official. [Diakses: 10-Mar-2018].

[9] G. A. Buntoro, “Analisis Sentimen Calon Gubernur DKI Jakarta 2017 Di Twitter," INTEGER: Journal of Information Technology, 2017.

[10]I. H. Witten, "Data mining with WEKA," Department of Computer Science University of Waikato New Zealand, 2013.

[11]R. Kohovi dan F. Provost, "Confusion matrix," Machine Learning, vol. 30, hlm. 271-274, 1998. 